\title{
Internet-Based Multi-Platform Thermometer Using WhatsApp and Sensor MLX90614 with Location Tracker Feature for Covid-19 Surveillance
}

\author{
Putra Wisnu Agung Sucipto ${ }^{1, *}$ Annisa Firasanti ${ }^{1}$
}

\author{
${ }^{1}$ Faculty of Engineering, Universitas Islam 45, 17113, Indonesia \\ *Corresponding author.Email: wisnu@unismabekasi.ac.id
}

\begin{abstract}
Daily monitoring of symptoms of high fever and contact tracing are the main steps in early detection of COVID-19 transmission. A person who is suspected of being infected with COVID-19 with symptoms of a high fever based on a record of his body temperature scan, must as soon as possible get activity surveillance. People with high fever symptoms should get detailed supervision regarding their movement so as not to pose a more severe risk. This study offers a noncontact human body temperature scanning technology without touching the skin, along with the ability to remember the identity of a person with high fever symptoms and the ability to trace his position immediately after the scan occurs. This feature is attached to a digital thermometer prototype that works on multi-platform operating systems. In addition, this technology is able to remotely distribute internet-based temperature scans using the WhatsApp social media network. Based on the results of trials that have been carried out on scanning human body temperature, this thermometer has worked as expected. The results of the temperature scan by the MLX90614 sensor which work in conjunction with Arduino and SIM900, have been able to send temperature data to the WhatsApp application. We have developed a regression formula for an additional treatment in the calibration of temperature measurements. The time required for the process of sending temperature data from the MLX90614 sensor to the WhatsApp application on the smartphone varies from 1 to 3 seconds.
\end{abstract}

Keywords: Fever, Position, MLX90614, WhatsApp, COVID-19.

\section{INTRODUCTION}

Tracking people with high fever must be done systematically to detect cases of transmission during the COVID-19 pandemic. This effort is taken in the context of health surveillance measures for early detection of infection symptoms. The surveillance team must be able to quickly find suspected patients who need to be supervised, contact tracing and follow-up reporting to the COVID-19 response task force as soon as possible [1].

Body temperature scanning can be done by measuring the temperature on the skin surface and core body. Both types of measurement methods use different temperature data collection techniques. Measurement on the skin needs to place the sensor on the surface of the skin to sample the temperature data on the skin surface. Meanwhile, the measurement of the core body temperature is done by implanting the sensor into the stomach to read the temperature directly from the body. The sensor that can be used for temperature measurement on the skin surface is the LM73 sensor which works in conjunction with an aluminum to scan the heat flux from the body [2], while the TMP112 sensor can be used for measuring the core body temperature [3].

Core body temperature measurement is normally performed using a tiny-sized thermometer based on nano technology. Nanotechnology allows a thermometer to work together with telecommunications equipment to transmit the scanned data out of the body. The data is then captured by smartphones and computers as collectors and collectors of scanned data [4]-[10].

The data transmission modules that are often used to deliver data packets over long distances are the RF, UHF, ZigBee, and Bluetooth modules [11]-[15]. Sometimes this transmission module also uses an embedded wireless internet network based on ARM [16]. The transmission of data packets is delivered to the receiving module through a series of addressing protocols [17]. In a further 
technical aspect, this packet transmission requires a cooperative strategy [18].

However, the aspect of sensor packaging and a small container coupled with the integration of communication equipment has not yet become the main function aspect required in a thermometer when it is used to scan a human body temperature during the current pandemic. The issue of size becomes the second aspect of consideration considering that even though the dimensions are small, the thermometer must still scan contactlessly in order to reduce the potential for droplet attachment in measuring instrument.

This research offers an effective technology that can be used to scan the body temperature of people with fever symptoms during the current pandemic. This technology is manifested in the form of a non-contact temperature scanning feature that is implanted in the thermometer. This thermometer works in a sophisticated way considering that it also includes the ability to track the whereabouts of people who have undergone a temperature scan by it. This sophistication is shown in the ability to recall the identity of people with high fever symptoms and the ability to trace their position immediately after the scan occurs. Thus, it is hoped that this technology will make it easier for the surveillance team to carry out daily monitoring, especially in the aspect of monitoring and monitoring body temperature as a vital sign of human health.

\section{METHOD}

This research has undergone a series of trials to investigate the performance of the thermometer prototype. The test was carried out by scanning the human body temperature. Selected a number of data samples taken from one man, one woman and a 2.5years-old girl. Each respondent was arranged not to be in activities with strenuous physical activities, to just sit and read or watch television.

Monitoring of body temperature in these two scenarios is carried out in a $9 \mathrm{~m}^{2}$ closed room with an air conditioner. Each temperature sample was taken at intervals of about 4-5 minutes. The number of samples taken was 10 data for each volunteer. The time for taking the temperature starts from 22.00 to 24.00 WIB. In addition, along with taking temperature data from this prototype, temperature data was also collected using a beurer FT 65 thermometer from [21]. This thermometer is used as a comparison instrument because it is a clinical thermometer which is usually used to scan human body temperature.

These sample data are then analyzed to measure device performance. The process of taking temperature data is carried out by several electronic devices configured as described in Figure 1.

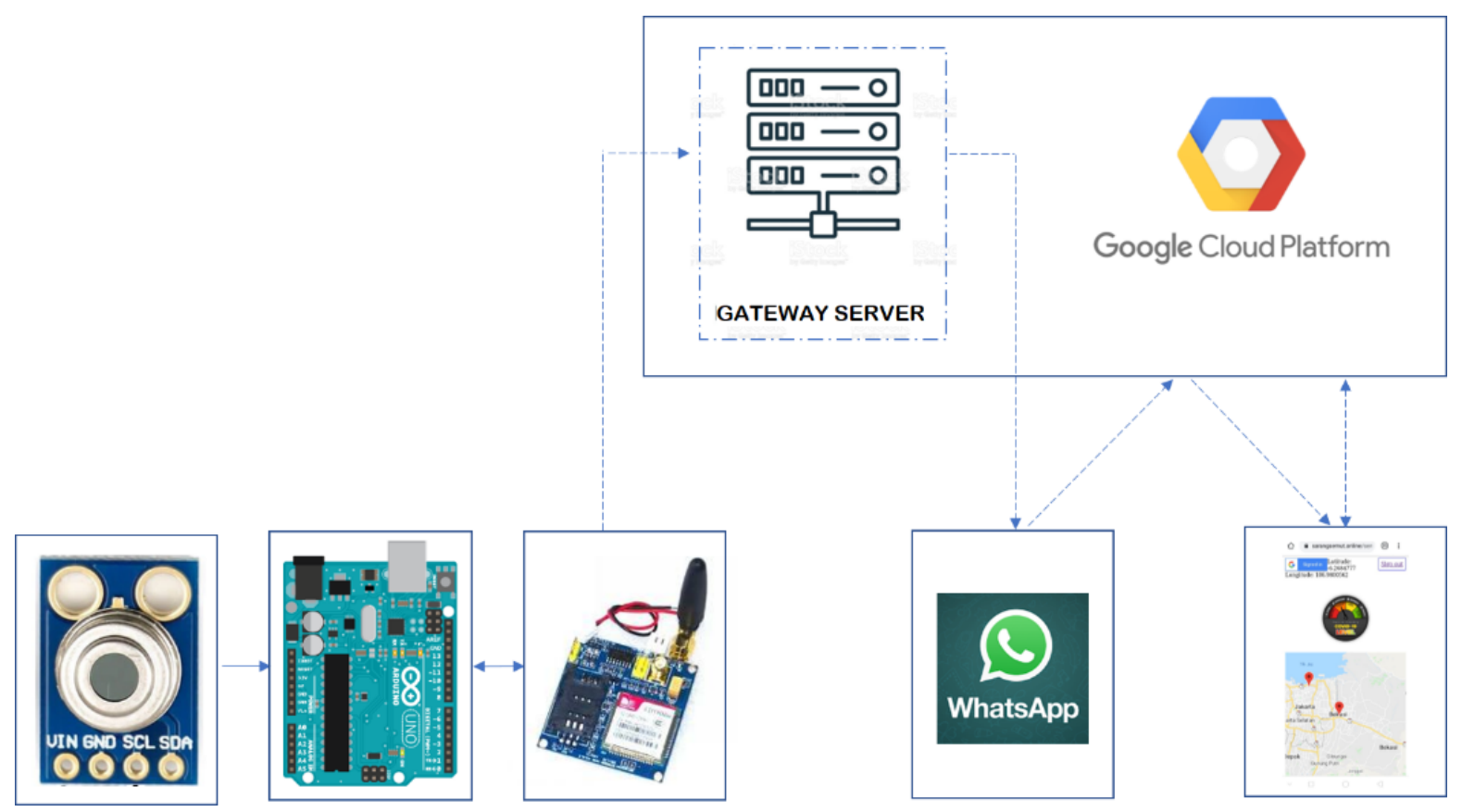

Figure 1 Device configuration of temperature scanner and location tracker

Based on Figure 1, the temperature data that has been scanned by the MLX90614 sensor will be forwarded to the SIM900 module. This module is connected to Arduino to forward temperature data to the gateway server. The SIM900 module communicates with Arduino via the RX and TX pins using the 9600 baudrate serial data communication protocol. Figure 2 describes in detail the MLX90614 sensor circuit scheme, ultrasonic sensor, LED, buzzer and SIM900. 


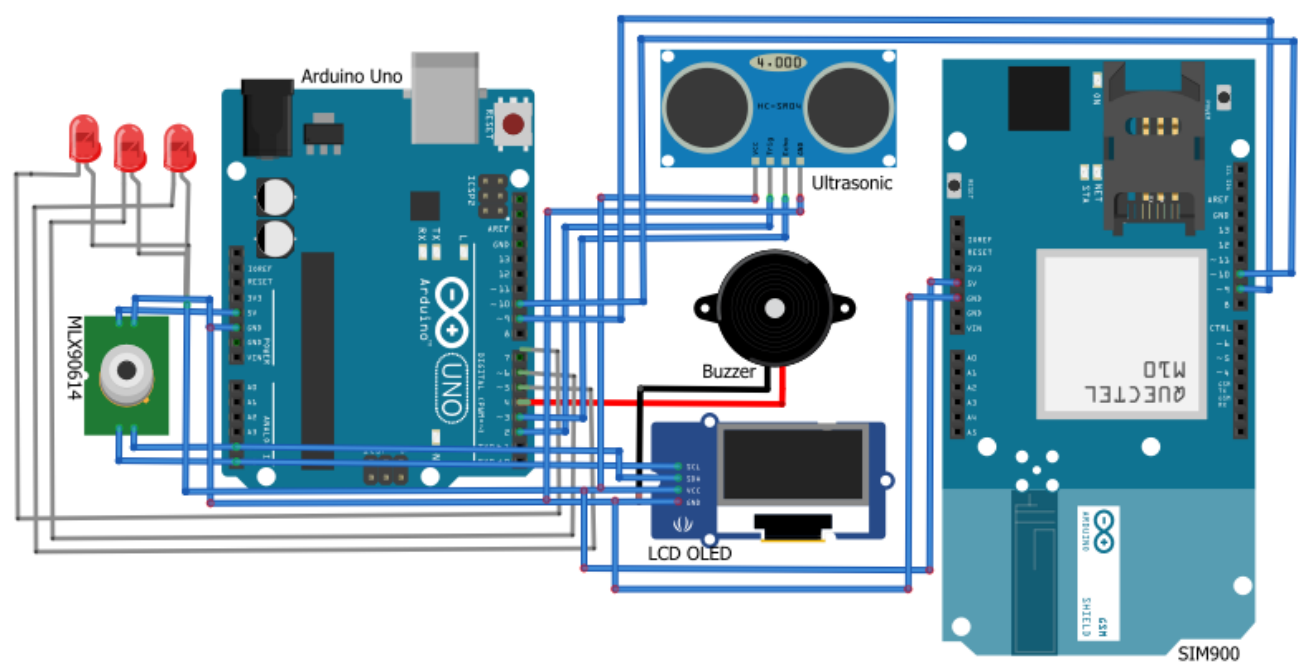

Figure 2 Circuit Scheme of Temperature Scanner and Location Tracker

The body temperature sample taken in this trial is the temperature around the forehead in the face area. Sampling was carried out with a sampling frequency of 1 sample per 100 milliseconds. In addition, there are three other devices integrated into the Arduino circuit: an ultrasonic sensor, a buzzer and a LED light. These three devices work as distance guides when placing the face in front of the MLX90614 sensor. The adjustable reading safety distance is about $5 \mathrm{~cm}$, as explained in [19][20].

Furthermore, an experiment was carried out by sending temperature sample data to the gateway server by SIM900 by utilizing GPRS services. This server is accessed via the URL www.sarangsemut.online. Data transmission to the gateway server uses the cellular network operator Telkomsel and AT Command as the basis for the instructions. If this initiation is successful, the HTTP GET Request initiation process will also proceeded. This process uses TCP and HTTP as data communication protocols which are executed by Arduino and SIM900 using AT Command HTTPACTION, HTTPPARA and HTTPREAD.

HTTP GET Request plays a role in distribution to data storage terminals. In this experiment, the gateway server communicates with the WhatsApp API to send messages to the WhatsApp network application as a data storage terminal. The WhatsApp API used in this sample test is the subscription API from https://chat-api.com/. Also, the Telegram application is used as a comparison. The Telegram API can be obtained after registration via BotFather Telegram.

The data arrived on these two social media is in the form of messages which is stored in the messaging box. The message sent is a narrative sentence containing the temperature data from the scan and a recommendation to report the whereabouts of the message recipient. This reporting is embedded behind the URL link www.sarangsemut.online/sensor/KirimLokasi.php.
Clicking on this URL link will trigger the process of identifying the latitude and longitude of the GPS sensor in the message recipient's smartphone. This identification requires using the Geolocation method in HTML 5 to activate the ask for location feature in the browser. After this request is approved, then this latitude and longitude data will be sent to the gateway server for marker determination in Google Map.

The use of Google Maps must use the Google + API and Google People which can be obtained by subscribing through the Google Cloud Platform at the URL https://console.cloud.google.com/. The data used through this API is a google account profile read through the profile.getEmail () and profile.getName () functions which describe the email address and username of the google account. Until this phase, the position of the message recipient has been traced and is ready to be installed on the google map.

Finally, a number of testing processes are carried out to see the performance of the device. The test process is testing the initiation of the GPRS service, IP request and HTTP GET Request to send messages from the gateway server to the smartphone. Then, testing the generation of latitude and longitude data and embedding a marker on the google map after testing the authentication of the google account by the message recipient is successful.

\section{RESULT AND DISCUSSION}

The results of this prototype hardware assembly are shown in Figure 4. Installed on this device a $9 \mathrm{~V} \mathrm{dc}$ battery as a voltage source. This battery has been able to turn on all electronic components in this prototype. Thus, triggering the GPRS service registration process and IP request to be able to connect to the internet network. The time needed for the registration process to get IP on this prototype is 8 seconds as described in Table 1. 
Table 1. Service Activation Experiment Result GPRS and IP Request

\begin{tabular}{lllll}
\hline No & \multicolumn{1}{c}{ Instruction } & \multicolumn{1}{c}{ Description } & Answer & Reply Time (ms) \\
\hline 1 & AT+CREG $=1$ & Entering cellular network & OK & 1000 \\
2 & AT+CGATT $=1$ & GPRS Service Initiation & OK & 1000 \\
3 & AT+CIPSHUT & GPRS Service Deactivation & SHUT OK & 1000 \\
4 & AT+CIPMUX $=0$ & Single IP connection Initiation & OK & 1000 \\
5 & AT+CSTT $="$ internet" & APN Telkomsel Initiation & OK & 1000 \\
6 & AT+CSTT? & Confirming APN & +CSTT: "internet","'","' & 1000 \\
7 & AT+CIICR & Starting GPRS connection & OK & 1000 \\
8 & AT+CIFSR & IP request & 10.16.214.187 & 1000 \\
\hline
\end{tabular}

We have also succeeded in conducting the process of scanning the human body temperature. Interestingly, in this trial, it was found that the data from the MLX90614 sensor was not entirely the same as the data generated from the Beurer and UT320D thermometers. This difference is very striking and it seems that the MLX90614 sensor needs additional treatment. This treatment is carried out so that the thermometer is standardized by the clinical thermometer used to scan the human body temperature. In this case, we carry out a regression process to make this thermometer able to catch up with the performance of the beurer's thermometer when scanning. Based on the experimental data obtained, the regression equation that can be made for this thermometer prototype is in formula (1). Figure 3 describes the details of the scan data distribution results and the graph of the regression equation.

$$
Y=22,09050511+0,44521165 X
$$

Where:

$$
\begin{aligned}
& \mathrm{Y}=\text { final Temperature Value }\left({ }^{\circ} \mathrm{C}\right) \\
& \mathrm{X}=\text { the measured temperature from sensor mlx } 90614
\end{aligned}
$$
$\left({ }^{\circ} \mathrm{C}\right)$

This data is then sent via WhatsApp and Telegram. The format of the message that appears on both social media is shown in Figure 4. In every social media, information on the temperature of the scan has been sent as well as a link to report the position. After clicking, the results of the formula position reporting are shown in Figure 6.c. From this image, the latitude and longitude data and the verified Google account authentication button is shown.

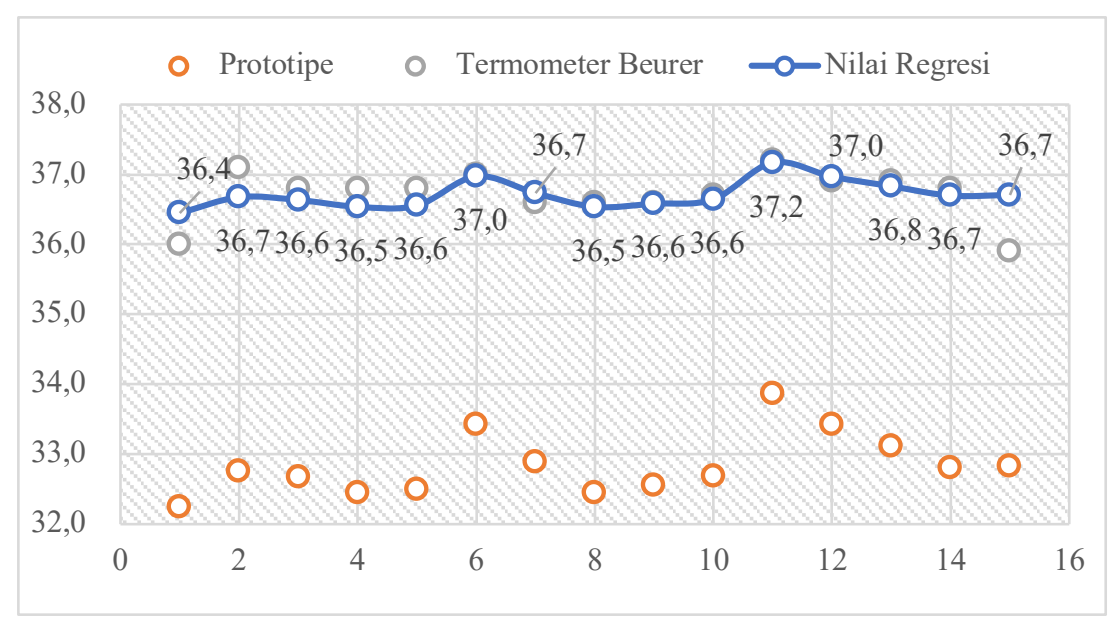

Figure 3 Graph of Regression Equation

Additionally, there are some slowdowns in the time when the messages are send to social media. In particular, when the data must be entered into the telegram. There are three classifications of time intervals that are read, namely: 1, 2 and 3 seconds. These three intervals were reviewed based on the customary length of data transmission. From the experimental data obtained, the $9^{\text {th }}$ and $10^{\text {th }}$ experiments recorded an interval of 3 seconds, for data entering the telegram. Typically, this interval is only about 1 second for the best time and around 2 seconds as the most frequent interval. From this, we argue that there have been 3 time-lapse classifications that cause the queue length to occur, namely the fast, average and longtime which quantitatively refers to these three groups of delays. Figure 5 illustrates the time interval classification data presentation. 
[Percobaan $1: 20.42]-H i$, pesan ini dari sarangsemut.online.

Suhu tubuh Anda, 37 derajat Celcius. Tetap jaga jarak dan selalu hidup sehat.

$\star \star \star$

Salam sehat selalu.

[KLIK] tautan ini untuk melaporkan posisi Anda saat ini, ya..!

www.sarangsemut.online/sensor/

KirimLokasi.php

20.42

(a)

"[Dari Gateway: 25-11-2020 | 23:12:38]-Hi, pesan ini dari sarangsemut.online. InSuhu tubuh Anda, 31.35 derajat Celcius. Tetap jaga jarak dan selalu hidup sehat. In ${ }^{\star * *}$ InSalam sehat selalu. In[KLIK] tautan ini untuk melaporkan posisi Anda saat ini, ya..! Inwww.sarangsemut.onlineV/sensorl /KirimLokasi.php"

(b)
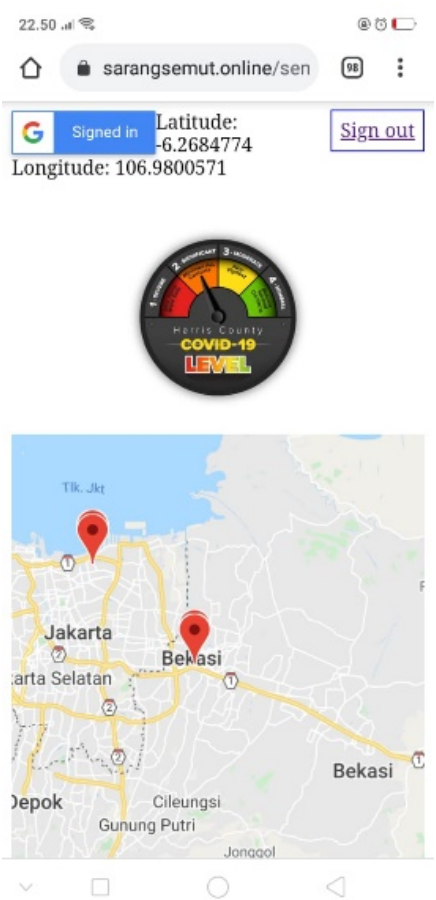

(c)

Figure 4 The display of inbox message in application (a) WhatsApp (b) Telegram (c) Maps Location of message receiver

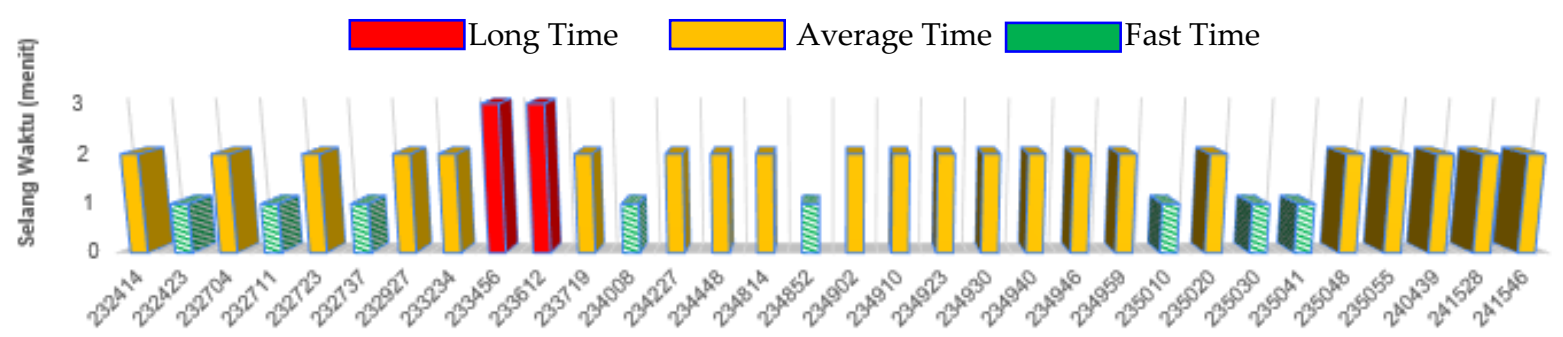

Waktu Percobaan

(a)

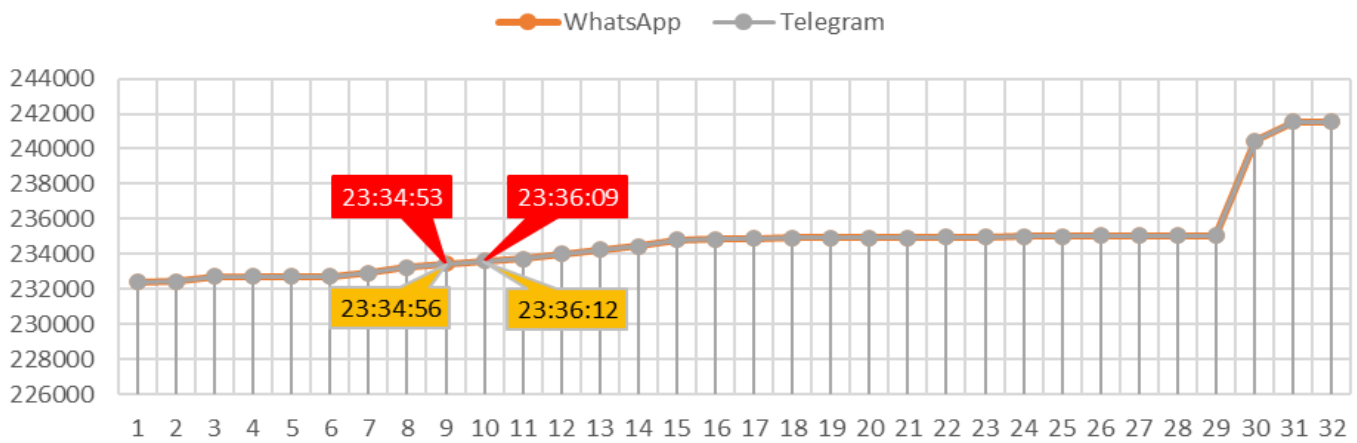

(b)

Figure 5 (a) Classification of the time interval for sending messages (b) An interval of 3 seconds when sending messages to telegram 


\section{CONCLUSION}

This research has succeeded in making appropriate technology that can be used to support the COVID-19 surveillance process, in the form of a thermometer that is integrated with internet networks and social media. With the non-contact temperature scanning feature and location tracking using Geolocation technology based on HTML 5, it is hoped that this will make it easier for the surveillance team to track the position of people with high fever. Special attention is needed regarding the performance of this thermometer when the data transmission process leaves the gateway server until it reaches the WhatsApp application on the smartphone. However, this situation does not interfere with the important role of Google Cloud Platform API, WhatsApp API and Gateway Server in providing remote data transmission channels based on HTTP and TCP / IP.

\section{REFERENCES}

[1] Kementrian Kesehatan Republik Indonesia, Pedoman Pencegahan dan Pengendalian Coronavirus Disease (COVID-19), Revisi ke., vol. 4, no. 3. Jakarta: Sub Direktorat Penyakit Infeksi Emerging, Direktorat Surveilans dan Karantina Kesehatan, Direktorat Jenderal Pencegahan dan Pengendalian Penyakit, Kementerian Kesehatan RI, 2020.

[2] M. Huang, T. Tamura, Z. Tang, W. Chen, and S. Kanaya, "A Wearable Thermometry for Core Body Temperature Measurement and Its Experimental Verification," IEEE J. Biomed. Heal. Informatics, vol. 21, no. 3, pp. 708-714, 2017.

[3] S. Yoshida, H. Miyaguchi, and T. Nakamura, "Development of basic system of ingestible core body thermometer with small size and low energy consumption powered by gastric acid battery," Proc. IEEE Sensors, vol. 2017-Decem, pp. 1-3, 2017.

[4] D. L. T. Wong et al., "An Integrated Wearable Wireless Vital Signs Biosensor for Continuous Inpatient Monitoring," IEEE Sens. J., vol. 20, no. 1, pp. 448-462, 2020.

[5] S. Lee et al., "All-Day Mobile Healthcare Monitoring System Based on Heterogeneous Stretchable Sensors for Medical Emergency," IEEE Trans. Ind. Electron., vol. 67, no. 10, pp. 88088816, 2019.

[6] S. G. M. Pereira, F. A. S. Medina, and D. S. D. Santos, "Temperature," vol. 15 , no. 11, pp. 22382243, 2017.

[7] T. Wu, F. Wu, J. M. Redoute, and M. R. Yuce, "An Autonomous Wireless Body Area Network
Implementation Towards IoT Connected Healthcare Applications," IEEE Access, vol. 5, no. c, pp. 11413-11422, 2017.

[8] G. Chen, T. Jiang, M. Wang, X. Tang, and W. Ji, "Modeling and reasoning of IoT architecture in semantic ontology dimension," Comput. Commun., 2020.

[9] J. Wannenburg and R. Malekian, "Body Sensor Network for Mobile Health Monitoring, a Diagnosis and Anticipating System," IEEE Sens. J., vol. 15, no. 12, pp. 6839-6852, 2015.

[10] J. P. Tello, O. Manjarres, M. Quijano, A. Blanco, F. Varona, and M. Manrique, "Remote monitoring system of ECG and human body temperature signals," IEEE Lat. Am. Trans., vol. 11, no. 1, pp. 314-318, 2013.

[11] Y. Chuo et al., "Mechanically flexible wireless multisensor platform for human physical activity and vitals monitoring," IEEE Trans. Biomed. Circuits Syst., vol. 4, no. 5, pp. 281-294, 2010.

[12] A. Vaz et al., "Full passive UHF tag with a temperature sensor suitable for human body temperature monitoring," IEEE Trans. Circuits Syst. II Express Briefs, vol. 57, no. 2, pp. 95-99, 2010.

[13] K. Malhi, S. C. Mukhopadhyay, J. Schnepper, M. Haefke, and H. Ewald, "A zigbee-based wearable physiological parameters monitoring system," IEEE Sens. J., vol. 12, no. 3, pp. 423-430, 2012.

[14] L. Wang et al., "A wireless biomedical signal interface system-on-chip for body sensor networks," IEEE Trans. Biomed. Circuits Syst., vol. 4, no. 2, pp. 112-117, 2010.

[15] O. S. Alwan and K. P. Rao, "Dedicated real-Time monitoring system for health care using ZigBee," Healthc. Technol. Lett., vol. 4, no. 4, pp. 142-144, 2017.

[16] S. Ding and X. Wang, "Medical remote monitoring of multiple physiological parameters based on wireless embedded internet," IEEE Access, vol. 8, pp. 78279-78292, 2020.

[17] J. Mu, X. Yi, X. Liu, and L. Han, "An Efficient and Reliable Directed Diffusion Routing Protocol in Wireless Body Area Networks," IEEE Access, vol. 7, pp. 58883-58892, 2019.

[18] Y. Peng and L. Peng, "A Cooperative Transmission Strategy for Body-Area Networks in Healthcare Systems," IEEE Access, vol. 4, no. c, pp. 91559162, 2016.

[19] I. D. Darwis, E. Basyar, and A. A. Adrianto, "Kesesuaian Termometer Digital Dengan 
Termometer Air Raksa Dalam Mengukur Suhu Aksila Pada Dewasa Muda," J. Kedokt. Diponegoro, vol. 7, no. 2, pp. 1596-1603, 2018.

[20] Sugiarti, "Non-Invasif Termometer: Temporal Artery Thermometer (TAT) Terintegrasi dengan Electronic Medical Record sebagai Peringkat
Teratas Metode Pengukuran Suhu pada Bayi dan Anak: Kajian Literatur," J. Kesehat., vol. 9, no. April, pp. 160-169, 2018.

[21]https://www.beurer.com/web/gb/products/medical/f ever-thermometers/ft-90.php 